\title{
DIFFERENTIAL EXPRESSION OF NADPH DIAPHORASE IN FUNCTIONALLY DISTINCT PREFRONTAL CORTICES IN THE RHESUS MONKEY
}

\author{
S. M. DOMBROWSKI* and H. BARBAS $\dagger \neq$ \\ *Department of Behavioral Neuroscience, Boston University School of Medicine, Boston, MA \\ $†$ Department of Health Science, Boston University, 635 Commonwealth Avenue, \#431, Boston MA, \\ 02215, and Department of Anatomy and Neurobiology, Boston University School of Medicine, and \\ New England Regional Primate Research Center, Harvard Medical School, Boston, MA
}

\begin{abstract}
The prefrontal cortex of primates is an integrative centre for sensory, cognitive, mnemonic and emotional processes. The cellular features which contribute to the functional specialization of its subsectors are poorly understood. In this study we determined the distribution of nicotinamide adenine dinucleotide phosphate-diaphorase-positive neurons in structurally and functionally distinct prefrontal cortices in the rhesus monkey. This class of neurons express nitric oxide synthase which is necessary for the production of nitric oxide, a novel neural messenger implicated in learning and memory. The density of diaphorase-positive neurons was approximately four times higher in olfactory areas than in eulaminate areas (areas 9,10,12,46, and 8), and two- to three-times higher in the agranular limbic area PAll than in eulaminate areas. Positive neurons were concentrated in a deep band (layers V and VI), a superficial band (layers II and upper III), and were sparsely distributed in the central, thalamic recipient zone (deep layer III, layer IV and upper V). The highest densities of positive neurons were observed in the white matter where their prevalence followed the opposite trend than in the corresponding overlying cortices. The distribution of diaphorase-positive neurons was correlated with the regional anatomic and functional specialization of prefrontal cortices. Thus, diaphorase-positive neurons were most densely distributed in orbital and then medial prefrontal limbic cortices which have a low cell density and widespread connections. In contrast, positive neurons were comparatively sparse in eulaminate cortices, which have a high cell density and more restricted connections.

These findings indicate that the distribution of diaphorase-positive neurons in prefrontal cortices is not random, but is associated with the structural architecture and functional attributes of these cortices. The preponderance of diaphorase-positive neurons in limbic cortices, which have been implicated in learning and memory, is consistent with the idea that nitric oxide may have a role in synaptic plasticity.
\end{abstract}

Key words: nitric oxide synthase, nitric oxide, limbic cortex, memory.

The prefrontal cortex of the rhesus monkey is a structurally and functionally heterogeneous region (for reviews, see Refs 7, 9, 37, 43 and 92). Prefrontal cortices are connected with every cortical sensory system and the motor cortices, and are thus capable of integrating information for action (for review, see Ref. 38). Among prefrontal cortices, the limbic areas, which are situated on the caudal orbital and medial surfaces, have the most distributed network. Their rich interconnections with diencephalic, temporal and cingulate structures, ${ }^{8,11,12,32,75,82,88}$ suggest that they are an integral part of a neural network involved in mnemonic processing.

The cellular features which may contribute to the functional specialization of prefrontal subareas are poorly understood. In the present study, we investi-

$\ddagger$ To whom correspondence should be addressed.

Abbreviations: DMSO, dimethylsulfoxide; NADPH, nicotinamide adenine dinucleotide phosphate; NADPHd, NADPH diaphorase; NO, nitric oxide; NOS, NO synthase. gated the organization of neurons which contain nicotinamide adenine dinucleotide phosphatediaphorase (NADPHd) in the prefrontal cortex. The significance of this class of neurons is based on their ability to synthesize nitric oxide (NO), a novel neural messenger which has been implicated in learning and memory ${ }^{18,80,99,125}$ (for review, see Refs $22,31,100$ ). NADPHd or nitric oxide synthase (NOS)-positive neurons appear to be resistant to destruction in Alzheimer's and Huntington's disease, ${ }^{35,59,62,77}$ to ischemia, aging and exposure to several different toxins $^{16,17,25,36,53-56,112}$ (for review, see Refs 28, 30). Neurons which contain diaphorase or NOS thus seem to form a unique subclass with specific properties.

To determine the distribution of NADPHd positive neurons in the prefrontal cortex we used a histochemical procedure. Our approach was based on findings which indicate that in the mammalian CNS, including the cortex, the distributions of neurons which have diaphorase activity and NOS largely coincide. ${ }^{21,29,45,47,63}$ In view of the above findings, 
in recent studies investigators have used the designation diaphorase and NOS interchangeably. ${ }^{102.122}$ It should be noted that the distribution of diaphorase-positive neurons in several neural structures had been described, albeit not quantitatively, prior to its association with NOS had been established. ${ }^{20.27,34,60,61.71-74,76,94-96,101.105,109,117,118}$ Nevertheless, several questions about the organization of diaphorase-positive neurons remain unresolved. For example, are diaphorase-positive neurons uniformly or differentially distributed in the heterogeneous expanse of the prefrontal cortex? If there are regional variations, are areas with high diaphorase expression unified by some common anatomic or functional attribute?

\section{EXPERIMENTAL PROCEDURES}

Data were obtained from brain tissue of five adult rhesus monkeys (Macaca mulatta). Experimental procedures were conducted according to the NIH Guide for the Care and Use of Laboratory Animals (NIH pub. No. 80-22, 1987). All efforts were taken to reduce the number of monkeys used and to minimize suffering. The monkeys had received small intracerebral injections of either horseradish peroxidase or fluorescent dyes in connection with other experiments. In the former, perfusion through the heart was initiated with saline, followed by 21 of fixative $(1.25 \%$ glutaraldehyde, $1 \%$ paraformaldehyde in phosphate buffer $(0.1 \mathrm{M}, \mathrm{pH} 7.4)$ delivered over a $30 \mathrm{~min}$ period, followed by perfusion with 21 of cold $\left(4^{\circ} \mathrm{C}\right)$ phosphate buffer. The brain then was removed from the skull, photographed, placed in glycerol phosphate buffer $(10 \%$ glycerol and $2 \%$ dimethylsulfoxide (DMSO) in $0.1 \mathrm{M}$ phosphate buffer at $\mathrm{pH} 7.4$ ) for one day and then transferred in $20 \%$ glycerol phosphate buffer for another two days. In animals injected with fluorescent dyes, perfusion was initiated with saline followed by $4 \%$ paraformaldehyde in $0.1 \mathrm{M}$ cacodylate buffer at $\mathrm{pH}$ 7.4. The brain then was placed in a solution of $4 \%$ paraformaldehyde with $10 \%$ glycerol and $2 \%$ DMSO for one day, and transferred to a solution containing $20 \%$ glycerol in $2 \%$ DMSO for another two days.

The brain was frozen in $-75^{\circ} \mathrm{C}$ isopentane $e^{90}$ and transferred to a freezing microtome. Sections were cut in the coronal plane at $40 \mu \mathrm{m}$ in 10 series, and collected in a solution of $0.1 \mathrm{M}$ phosphate buffer $(\mathrm{pH}$ 7.4). Adjacent series of sections were stained for Nissl bodies, myelin, and acetylcholinesterase to aid in delineating architectonic borders. ${ }^{41.42}$

\section{NADPH diaphorase staining}

Recent biochemical and histochemical evidence indicates that, at least in the central nervous system of mammals, NADPHd is a good marker for NOS. ${ }^{45,47,63}$ In the Results we use the terms NADPHd or diaphorase for consistency.
Staining for diaphorase was performed by using a slight modification of methods previously described..$^{34,97,110}$ Freefloating sections were washed three times $(10 \mathrm{~min}$ each) at $37^{\circ} \mathrm{C}$ in $0.1 \mathrm{M}$ Tris- $\mathrm{HCl}$ buffer ( $\mathrm{pH}$ 7.4). The tissue was then incubated at $40^{\circ} \mathrm{C}$ in $0.1 \mathrm{M}$ Tris- $\mathrm{HCl}$ buffer containing $0.8 \mathrm{mM} \beta$-nicotinamide adenine dinucleotide phosphate, reduced form (NADPH, Sigma N-1630), $0.8 \mathrm{mM}$ Nitro Blue Tetrazolium (Sigma N-6876), 0.1\% Triton-X, and $0.16 \%$ malic acid for $60-90 \mathrm{~min}$ with constant agitation. Sections then were washed three times $(10 \mathrm{~min}$ each) in $0.1 \mathrm{M}$ Tris- $\mathrm{HCl}$ buffer, mounted on chrome-alum coated slides and allowed to dry. Sections were then counterstained in $1 \%$ Neutral Red solution, dehydrated through graded alcohols $(70-100 \%)$, cleared in xylene and coverslipped with Permount (Fisher Scientific). In control experiments either NADPH or Nitro Blue Tetrazolium were omitted but all other steps were identical to the experimental.

\section{Data acquisition}

Brain sections prepared according to the above method were viewed microscopically under bright-field illumination. Drawings of brain sections through the prefrontal and adjacent cortices, diaphorase-positive neurons, and the site of blood vessels used as landmarks were transferred from the slides onto paper using a digital plotter (Hewlett Packard 7475A) electronically coupled to the stage of the microscope and to a computer (Compaq 386). The analogue signals were converted to digital signals via an analogue-todigital converter (Data Translation) in the computer. Each diaphorase-positive neuron was recorded by aligning the centre of the cross hair (permanently fixed in one eyepiece of the microscope) with the centre of the labelled neuron and pressing a button. The location of diaphorase-positive neurons was recorded using different symbols and colours to indicate labelled neurons in layers I-III, layers IV-VI, proximal white matter, and deep white matter. Software developed in this laboratory ensured that each labelled neuron was recorded only once.

\section{Data analysis}

The frontal cortices were reconstructed serially using the suici as landmarks and are shown on diagrams of the surface of the cortex. Unfolded maps of the cortex were prepared according to a method described previously. ${ }^{6.13}$ References to architectonic areas of the prefrontal cortex are according to a classification described previously..$^{14}$

Areal measures and the number of diaphorase-positive neurons for superficial (layers I-III) and deep (layers IV-VI) cortical layers, proximal white matter, and deep white matter below each architectonic area were counted separately in every section. For purposes of analysis, the white matter was also subdivided into its deep and proximal part (Table 1); the latter lies just below layer VI and corresponds to the region which includes the cortical association fibres. ${ }^{78}$ Labelled neurons in the white matter were concentrated either superficially just below layer VI, or in a deep zone which is situated below the proximal white matter zone. A central region in the white matter was devoid of labelled neurons and served as an arbitrary demarcation zone between the superficial and deep white matter. In areas where

Abbreviations used in the table and figures

$\begin{array}{ll}\text { A } & \text { arcuate sulcus } \\ \text { CC } & \text { corpus callosum } \\ \mathrm{Cg} & \text { cingulate sulcus } \\ \mathrm{cl} & \text { claustrum } \\ \mathrm{G} & \text { gustatory } \\ \text { Iag } & \text { insula, agranular } \\ \text { IdgI } & \text { Insula, dysgranular } \\ \text { LF } & \text { lateral fissure } \\ \text { LO } & \text { lateral orbital sulcus }\end{array}$

$\begin{array}{ll}\text { MO } & \begin{array}{l}\text { medial orbital sulcus } \\ \text { OLF }\end{array} \\ & \begin{array}{l}\text { nuctory: olfactory tubercle, anterior olfactory } \\ \text { principal sulcus }\end{array} \\ \text { P } & \text { prepiriform cortex } \\ \text { PAll } & \text { periallocortex } \\ \text { Pro } & \text { proisocortex } \\ \text { ProM } & \text { rostral portion of the ventral premotor cortex } \\ \text { Ro } & \text { rostral sulcus }\end{array}$


sulci are apposed, the deep white matter was divided equally between the two areas.

Cell counts and areal extent were made using a microscope/computer interface as described previously. ${ }^{12}$ Density values were calculated as the number of diaphorase-positive neurons per unit area $\left(\mathrm{mm}^{2}\right)$. "Total area" density in the Results refers to the sum of all labelled neurons in each cortical area and the underlying white matter $\left(\mathrm{mm}^{2}\right)$. In Table 1 and in Results, "Total cortex" refers to the overall density of labelled neurons $/ \mathrm{mm}^{2}$ in all cortical layers for each area; "Total white matter" refers to the overall density of labelled neurons $/ \mathrm{mm}^{2}$ in the white matter below each area or group of areas (Table 1).

\section{RESULTS}

\section{General observations}

The results are based on observations made in five adult rhesus monkeys. Diaphorase-positive neurons contained a blue reaction product and were clearly seen against a background of unlabelled neurons counterstained with Neutral Red. Positive staining distinguished the cell body and extensive branching of processes. There was no staining in control sections in which either NADPH or Nitro Blue Tetrazolium were omitted.

The regional distribution of diaphorase-positive neurons was similar among the cases, although the overall density differed to some extent. Detailed quantitative analyses were made in three cases. In case AN the regional density was $1.5-6.69$ positive neurons per $\mathrm{mm}^{2}$, in case AP it was 2.95-13.11, and in case EU it was 0.77-6.88. Differences in the overall density values may be due to different perfusion methods. ${ }^{24,69,120}$ However, because we found no consistent differences that could be attributed to the perfusion, overall differences in density may reflect individual variation among monkeys.

\section{Areal distribution of diaphorase-positive neurons}

The areal distribution of positive neurons is shown in two cases on reconstructed maps of the frontal cortices and in coronal sections in Figs 1 and 2. The density of labelled neurons is shown in Table 1 . The overall density of positive neurons was highest in

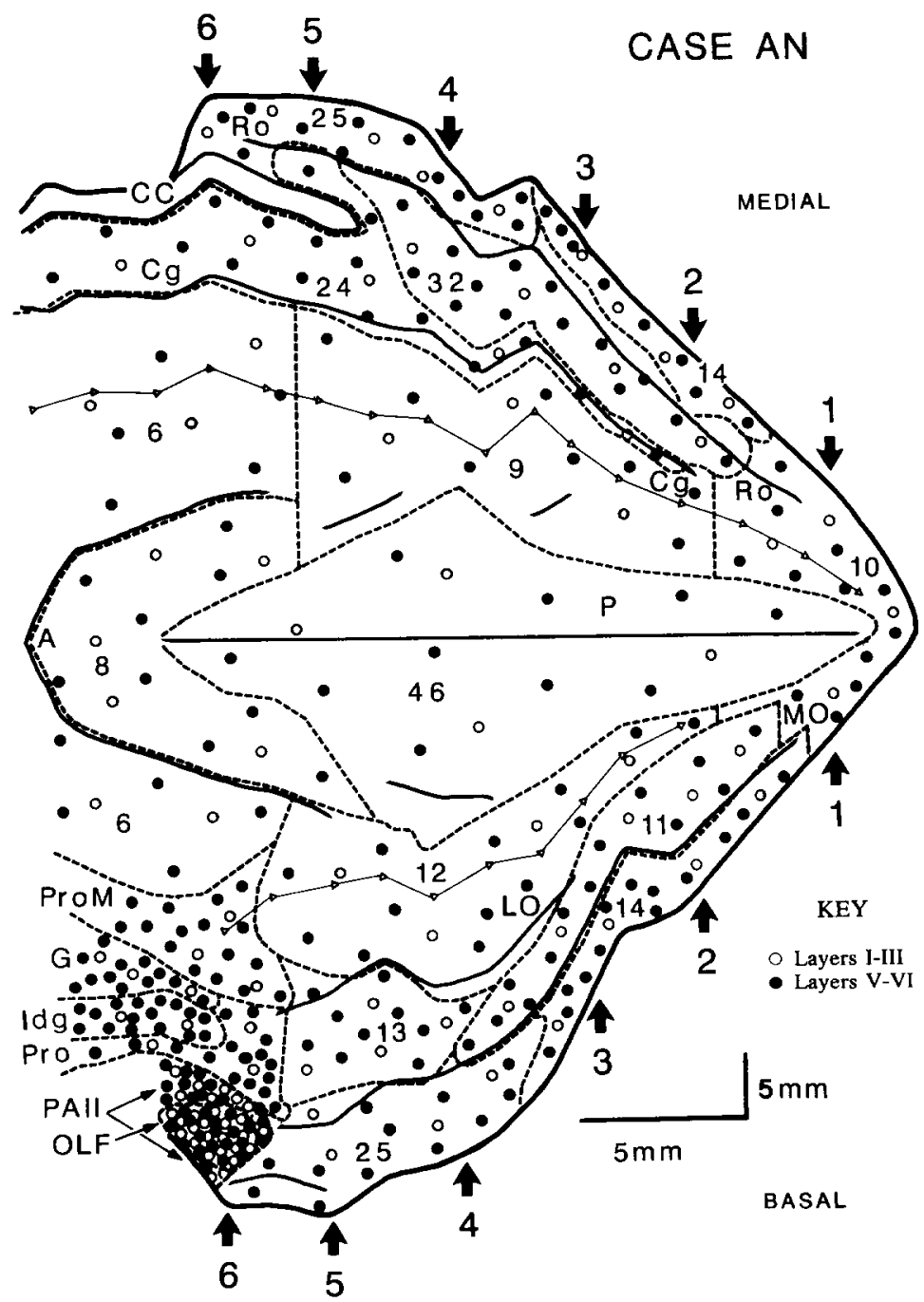

Fig. 1(a) Caption on page 53. 


\section{CASE AN}

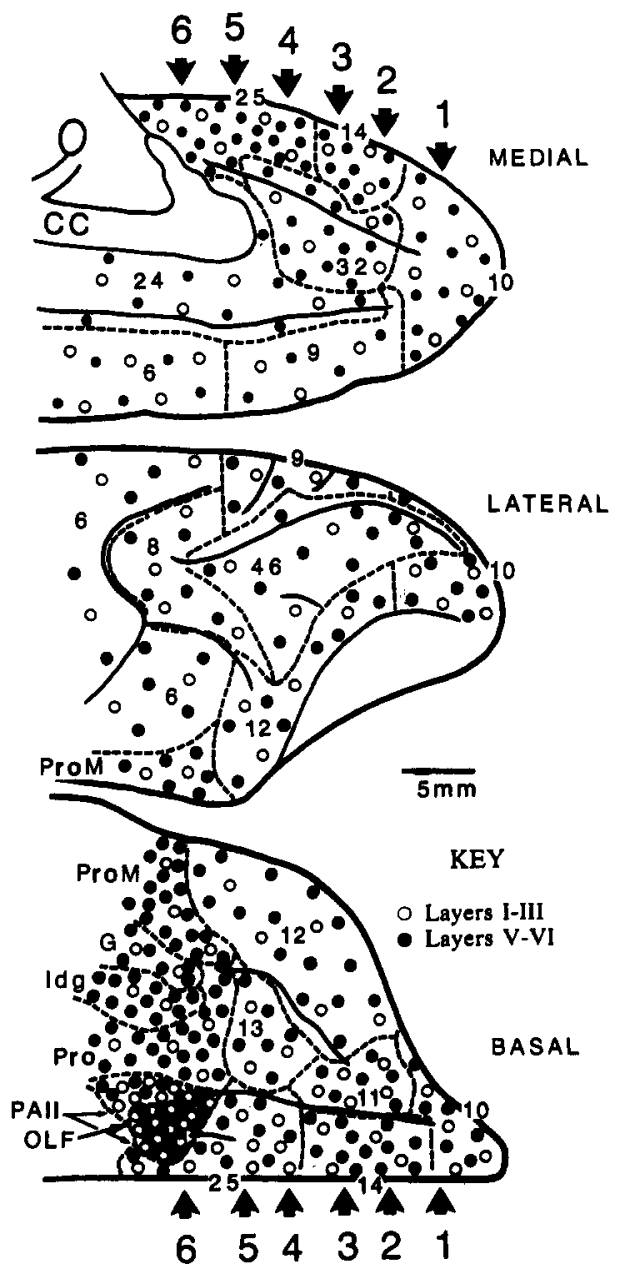

Fig. 1(b) Caption opposite.

caudal orbital areas and the adjacent insular areas, followed by rostral orbital and medial areas, and was lowest in lateral prefrontal areas (Table 1; Figs 1-3).

Among caudal orbital areas, labelled neurons were most prevalent in the primary olfactory areas (Table 1; Figs 1A bottom; 1B bottom; 1C section 6; 2 bottom; 3A, D), followed by areas PAll, Pro, the dysgranular insula (Idg) and the gustatory $(G)$ area (Table 1). In rostral orbital areas, the density of diaphorase-positive neurons was somewhat lower than in the caudal areas (Figs 1A bottom; $1 \mathrm{~B}$ bottom; 1C; 2 bottom).

Medial prefrontal cortices showed the next highest regional density of positive neurons (Figs 1A top; 1B top; $1 \mathrm{C} ; 2$ top; 3B, E). Among medial areas, the highest density of positive neurons was observed in the medial part of area 25 , followed by areas 24,32 , and 14 and then the medial parts of areas 10 (M10) and 9 (M9; Figs 1A top; $1 \mathrm{~B}$ top; 2 top).

The incidence of positive neurons was lowest in lateral prefrontal areas, particularly in lateral areas
10 (L10) and 12 (L12), and dorsal areas 10 (D10) and 9 (D9; Figs. 1A centre; 1B centre; 1C; 2 centre; $3 C, F)$. Among lateral cortices, areas 46, 8, and 6 had an intermediate density of positive neurons.

\section{Regional distribution of diaphorase-positive neurons}

We combined data from prefrontal areas with similar laminar definition to determine whether regional differences in the distribution of labelled neurons were related to differences in laminar characteristics noted previously. ${ }^{14}$ Categories were constructed on the basis of number of layers and laminar definition, and are shown in Table 1. At one extreme olfactory paleocortical areas have either a nuclear appearance (e.g., anterior olfactory nucleus) or are organized into three layers (e.g., prepiriform cortex). The second category included the agranular area PAll, and the third category included all dysgranular areas. Agranular and dysgranular association cortices are collectively called limbic. The following three categories included eulaminate areas, which have six layers, but nevertheless show small differences in laminar distinction. They were grouped in an ascending order for laminar definition. The distribution of positive neurons in premotor area 6 was similar to the last group and is illustrated in Figs 1 and 2. The values for area 6 are not included in Table 1 because they were not computed beyond the caudal limit of the prefrontal cortex at the spur of the arcuate sulcus.

We first examined whether regional variations of labelled neurons were consistent among cases. The regional distribution of diaphorase-positive neurons among cases was highly correlated (rank order; $P<0.02$ ). As shown in Fig. 4A, where the six cortical categories were ranked by density of labelled neurons, the plots among cases were virtually identical. This indicates that the regional distribution of labelled neurons was similar among cases. We then examined whether the regional differences in the distribution of positive neurons were statistically significant. An analysis of variance showed overall significant differences in total cortical density of NADPHd-positive neurons among the cortical categories $(F=5.27, P<0.01)$. The regional distribution of diaphorase-positive neurons (Table 1, "Total cortex") was approximately four times higher in olfactory areas (category 1) than in eulaminate areas (categories 5 and 6), and their density in the agranular area PAll (category 2) was 2-3 times higher than in eulaminate areas (Table 1). The density of labelled neurons in dysgranular areas (category 3 ) fell between the above two extremes.

\section{Diaphorase-positive neurons in the white matter}

Numerous positive neurons were noted in the white matter below all cortical areas (Figs $1 \mathrm{C} ; 3$; 5). The white matter had an overall higher density of labelled neurons than the overlying cortical areas, with the exception of the olfactory cortex and area PAll, 

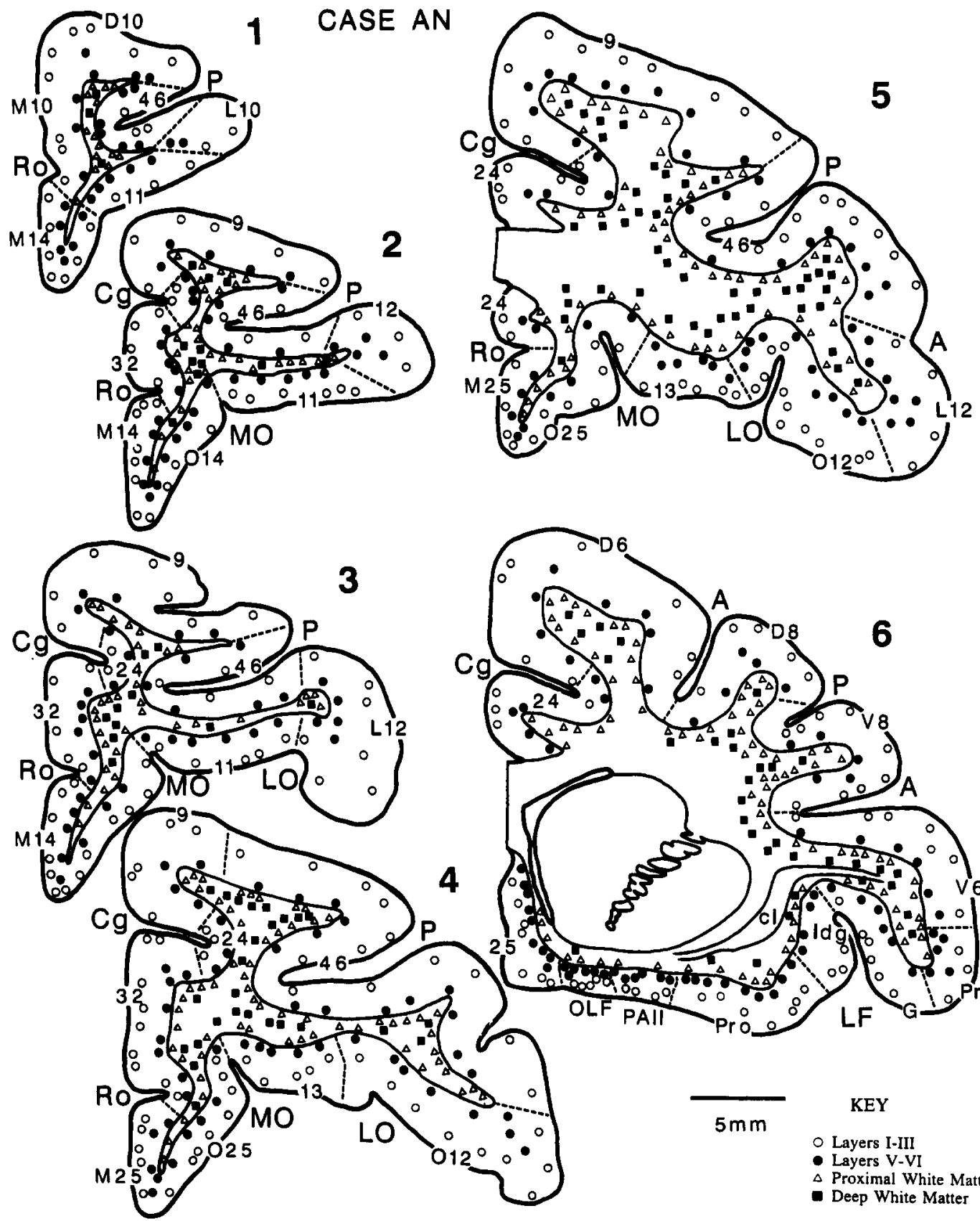

3

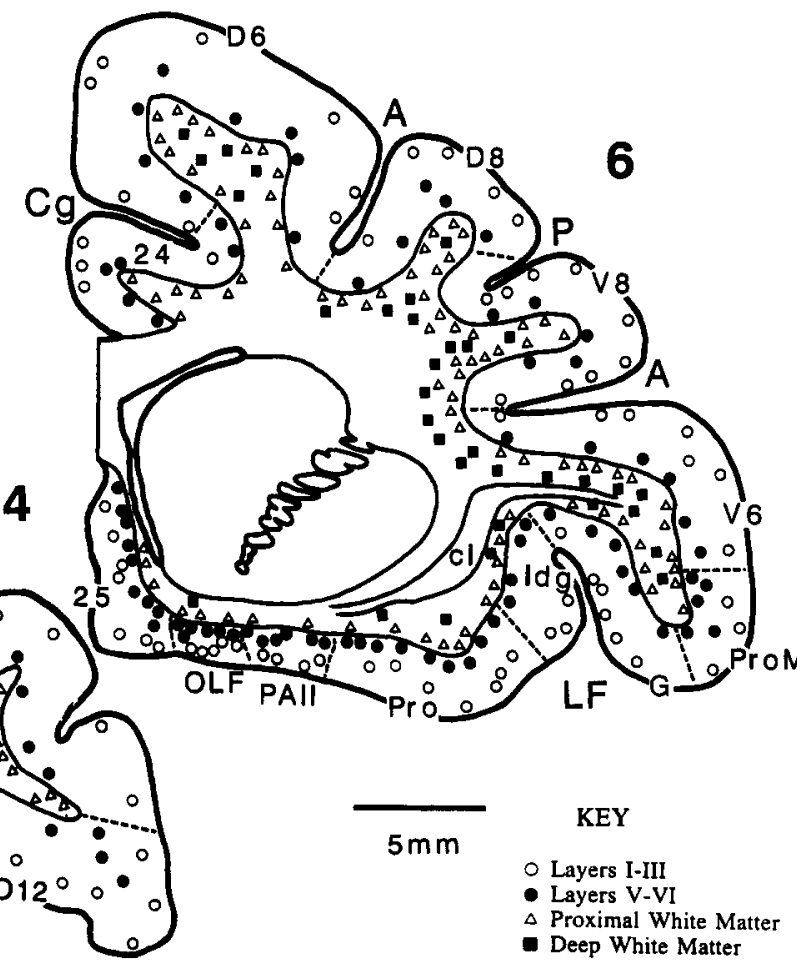

Fig. I(c).

Fig. 1. The distribution of diaphorase positive neurons in the cortex in case AN is shown on an unfolded map of the frontal cortex (a); on the medial, lateral, and basal surfaces of the cortex (b); and in diagrams of coronal sections (c) in rostral (1) through caudal (6) prefrontal levels taken at the levels indicated by arrows in parts $a$ and $b$. Medial is to the left. The symbols here and in Fig. 3 are as follows: open circles represent labelled neurons in layers I-III, filled circles in layers IV-VI, triangles in proximal white matter, black squares in the deep white matter. The density of symbols in the maps is proportional to the overall density of diaphorase-positive neurons in each cortical area, or in the white matter below each area (see Table 1). Architectonic areas are separated by dashed lines. Medial, lateral, and basal surfaces in part a are separated by a thin line with triangles.

where the inverse relationship was observed (Table 1, compare "Total cortex" with "Total white matter"). The density of diaphorase-positive neurons in the underlying white matter ranged from 4.56 to
$9.42 / \mathrm{mm}^{2}$ in case $\mathrm{AN}$, and 1.05 to $6.07 / \mathrm{mm}^{2}$ in case AP (Table 1). Within the white matter the highest density of labelled neurons was noted below areas 46 , 8 , lateral areas 10 and 12 , and dorsal areas 10 and 9 


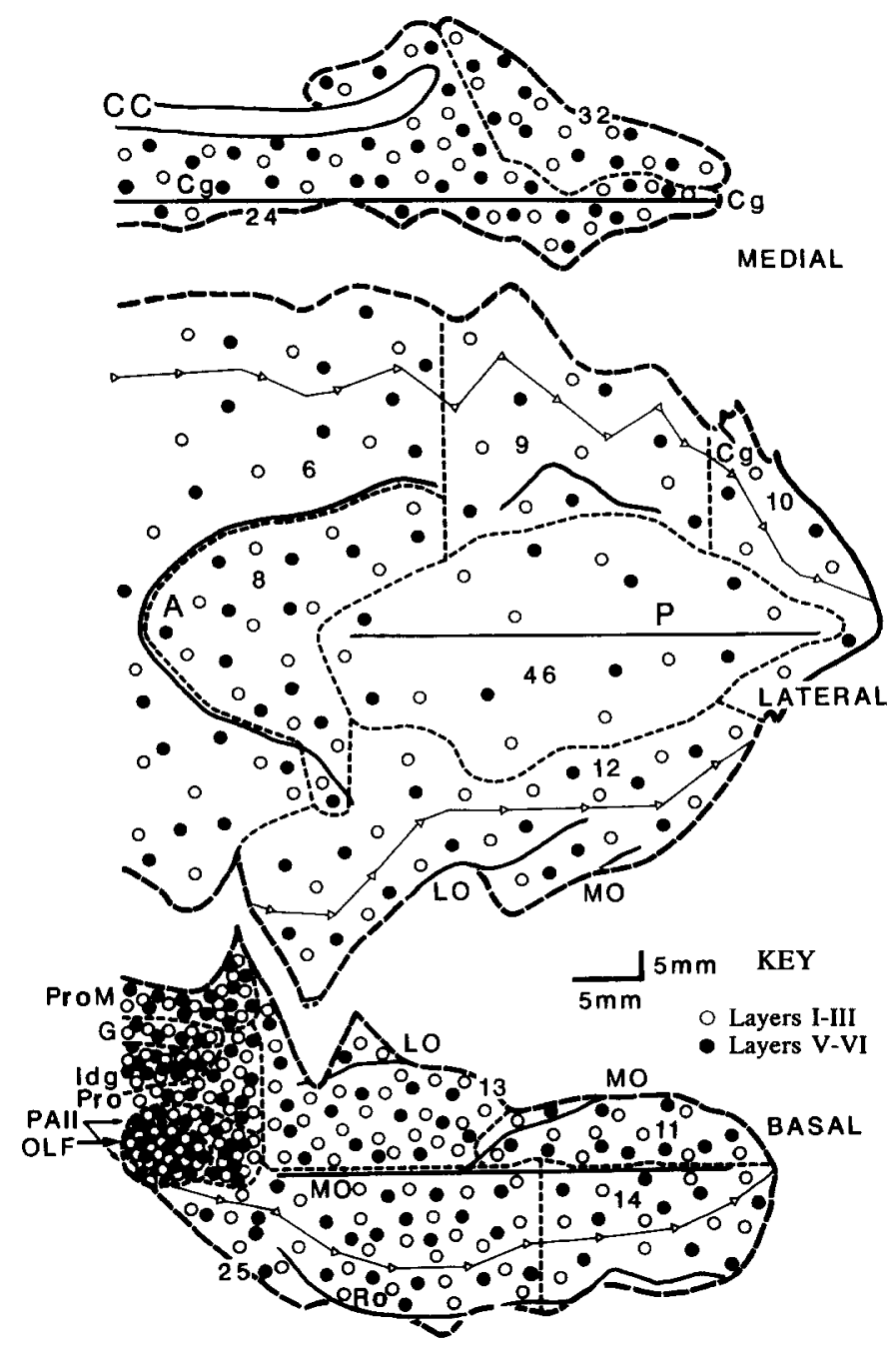

Fig. 2. The distribution of diaphorase-positive neurons in case AP is shown on the medial, lateral, and basal surfaces. Each surface was reconstructed separately to minimize angular distortion. The straight line along a sulcus in each surface shows the reference for each view. The medial parts of areas 10 and 9 and the orbital part of area 12 have been included in the lateral surface in order to preserve the continuity of the areas. Similarly, medial parts of areas 25 and 14 have been included with the basal surface.

(Table 1; Figs 1C; 3C, F; 5). The next highest density of positive neurons was seen below rostral orbital and medial areas (areas 11, 13, 24, 32, 14 and 25; Table 1; Figs $1 \mathrm{C} ; 3 \mathrm{~B}, \mathrm{E}$ ), and the lowest density was noted below the olfactory cortex, areas PAll, Pro, and the agranular and dysgranular parts of the insula (Table 1; Figs 1C; 3A, D). As shown in Fig. 4B, the regional density of labelled neurons in the white matter was inversely related to its regional distribution in the overlying cortex.

Laminar and white matter distribution of diaphorasepositive neurons

In eulaminate and dysgranular areas the upper layers include layers I-III, and the deep include layers IV-VI. In the agranular area PAll and the olfactory prepiriform area, which have only three distinguishable layers, ${ }^{14}$ the superficial zone includes layers I and II and the deep zone includes layer III. In some olfactory areas, such as the olfactory tubercle, where no clear lamination can be observed in the rhesus monkey, the division into upper and lower layers was made by bisecting each area.

In most areas the relative distribution of diaphorase-positive neurons in the cortex was higher in the deep layers than in the upper layers (Table 1, layers IV-VI and layers I-III). The above observation may be attributed to the inclusion of the cell-sparse layer I with the upper layers. However, our findings indicated that excluding layer I did not change signifcantly the overall trend of densities by layers in most areas. In the white matter, the distribution of 
diaphorase-positive neurons was higher in its proximal than in its deep component (Table 1; Figs $1 \mathrm{C} ; 5$ ).

Positive neurons in the cortex were arranged into two distinct bands: one was concentrated in the deep part of the infragranular layers, and the other occupied layers II and the upper part of layer III. The arrangement of positive neurons into a deep and a superficial band left a central zone where positive neurons were comparatively sparsely distributed (Fig. 1C). The latter included the deep part of layer III, granular layer IV, and the upper part of layer $\mathrm{V}$.

\section{Other labelling}

We made a few observations on overall background activity and fibre distribution in the cortex. There was a dense and diffuse plexus of positive activity in the olfactory cortex which included a superficial and a deep component (Fig. 3A). Similarly, the indusium griseum showed dense background activity. We could not determine whether this activity was a result of extensive dendritic or axonal branching or even if it occupied extracellular as well as intracellular compartments. This pattern of overall background labelling was unique to the above structures among those examined.

We also noted a horizontally oriented strip of positive fibres in the central part of layer $I$, which was particularly prominent in eulaminate areas 8 and 46 (Figs 3C; 6A). In contrast, in limbic areas positive processes in layer I were diffusely distributed and less prominent (Figs 3B; 6B). Fibre labelling in layer I was sparse or absent in the olfactory cortex (Fig. 3A).
DISCUSSION

\section{Technical considerations}

Previous studies have shown that diaphorase label is sensitive to fixation treatments. ${ }^{33,67,111}$ The overall differences in label that we noted among cases may be attributed to inadvertent differences in fixation, or may reflect individual differences among animals (Table 1). In spite of the differences in the overall density, the pattern of the regional distribution of positive neurons across architectonic areas and in the white matter was strikingly similar in different animals (Fig. 4A). These findings suggest that in normal monkeys, while the overall number of positive neurons varies among animals, the pattern of their regional distribution appears to be strictly regulated.

\section{Diaphorase expression is high in limbic cortices}

The distribution of diaphorase-positive neurons differed considerably within prefrontal areas in a strikingly similar pattern in all animals. Olfactory and limbic prefrontal cortices had the highest density and eulaminate cortices had the lowest density of diaphorase-positive neurons. The results suggest that the differences in the expression of diaphorase coincide broadly with the structural differences noted in the prefrontal cortices of the rhesus monkey. ${ }^{7,9,14,15}$ Thus, as the degree of laminar definition increases from agranular limbic to dysgranular limbic and then to eulaminate areas, the density of diaphorasepositive neurons decreased.

Our results indicated that positive neurons in the cortex were concentrated in a superficial band (layers II, the upper part of layer III) and a deep band (deep part of layer $\mathrm{V}$ and layer VI), and were sparsely

Table 1. Density ${ }^{\circ}$ of NADPH diaphorase positive neurons in layers I-III, IV-VI and the white matter of prefrontal and adjacent cortices**

\begin{tabular}{|c|c|c|c|c|c|c|c|}
\hline \multirow{2}{*}{$\begin{array}{c}\text { CASE: AN } \\
\text { Area }\end{array}$} & \multirow{2}{*}{\multicolumn{2}{|c|}{$\begin{array}{c}\text { Cortex } \\
\text { I-III IV-VI }\end{array}$}} & \multicolumn{2}{|c|}{ White matter } & \multirow{2}{*}{$\begin{array}{l}\text { Total } \\
\text { cortex }\end{array}$} & \multirow{2}{*}{$\begin{array}{c}\text { Total } \\
\text { white matter }\end{array}$} & \multirow{2}{*}{$\begin{array}{l}\text { Total } \\
\text { area }\end{array}$} \\
\hline & & & Proximal & Deep & & & \\
\hline 1. OLF* & 4.35 & 8.41 & 4.25 & 0.47 & 6.69 & 4.72 & 6.35 \\
\hline 2. PAll* & 3.69 & 6.6 & 3.6 & 0.96 & 5.43 & 4.56 & 5.21 \\
\hline 3. Pro, ProM, G, Idg, 25, 13, 24, 32 & 0.95 & 3.45 & 6.07 & 2.5 & 1.91 & 8.57 & 3.62 \\
\hline 4. $14, \mathrm{O} 12,11, \mathrm{M} 10, \mathrm{M} 9$ & 0.99 & 3.41 & 4.76 & 1.91 & 1.82 & 6.67 & 2.81 \\
\hline 5. L10, L12, R46, D9, D10 & 0.93 & 2.45 & 6.63 & 2.79 & 1.5 & 9.42 & 2.59 \\
\hline 6. $\mathrm{C} 46, \mathrm{~V} 8, \mathrm{D} 8$ & 1.18 & 2.33 & 5.11 & 2.37 & 1.65 & 7.48 & 3.15 \\
\hline CASE: AP & Cor & tex & White $\mathrm{m}$ & ter & Total & Total & Total \\
\hline Area & I-III & IV-VI & Proximal & Deep & cortex & white matter & area \\
\hline 1. OLF* & 19.15 & 8.81 & 1.05 & 0 & 13.11 & 1.05 & 9.39 \\
\hline 2. PAll* & 6.65 & 7.12 & 4.17 & 0 & 6.89 & 4.17 & 6.5 \\
\hline 3. Pro, ProM, G, Idg, 25, 13, 24, 32 & 5.46 & 5.18 & 4.89 & 0.75 & 5.35 & 5.64 & 5.42 \\
\hline 4. $14, \mathrm{O} 12,11, \mathrm{M} 10, \mathrm{M} 9$ & 3.24 & 3.51 & 4.64 & 4.13 & 3.36 & 6.07 & 3.92 \\
\hline 5. L10, L12, R46, D9, D10 & 2.59 & 3.47 & 3.56 & 1.54 & 2.95 & 5.1 & 3.37 \\
\hline 6. C46, V8, D8 & 3.94 & 4.34 & 3.47 & 1.11 & 4.14 & 4.57 & 4.27 \\
\hline
\end{tabular}

Density $=$ neurons $/ \mathrm{mm}^{2}$.

*Olfactory cortices and area PAII have only three layers. The superficial layers (I and II) are represented under the column CORTEX I-III and the deep layer (III) under the column CORTEX IV-VI.

**Areas were grouped into six categories according to the degree of their laminar definition. Category 1 represents olfactory areas and category 6 the best delineated eulaminate areas.

A letter before an architectonic area indicates: $\mathrm{C}$, caudal; D, dorsal; L, lateral; M, medial; $\mathrm{O}$, orbital; R, rostral; V, ventral. 
distributed in deep layer III and layer IV, which are recipient of thalamic projections (for review, see Ref. 52). These results are consistent with the observations of other investigators. ${ }^{45} \mathrm{We}$ also noted that positive fibres in layer I of eulaminate areas formed a horizontal strip which contrasted sharply with their scattered ramification in limbic cortices (Figs 3B, C; 6). The above observations suggest that there are differences in the pattern of branching of processes of diaphorase-positive neurons in limbic and in eulaminate areas.
Relationship of diaphorase-positive neurons in the cortex and white matter

Diaphorase-positive neurons were densely distributed in the white matter below layer VI. In fact, in most areas the overall density of positive neurons was higher in the white matter than in the overlying cortex. There are several explanations for the strong presence of diaphorase-positive neurons in the white matter in adult primates. First, their presence in the proximal white matter, in a position previously held
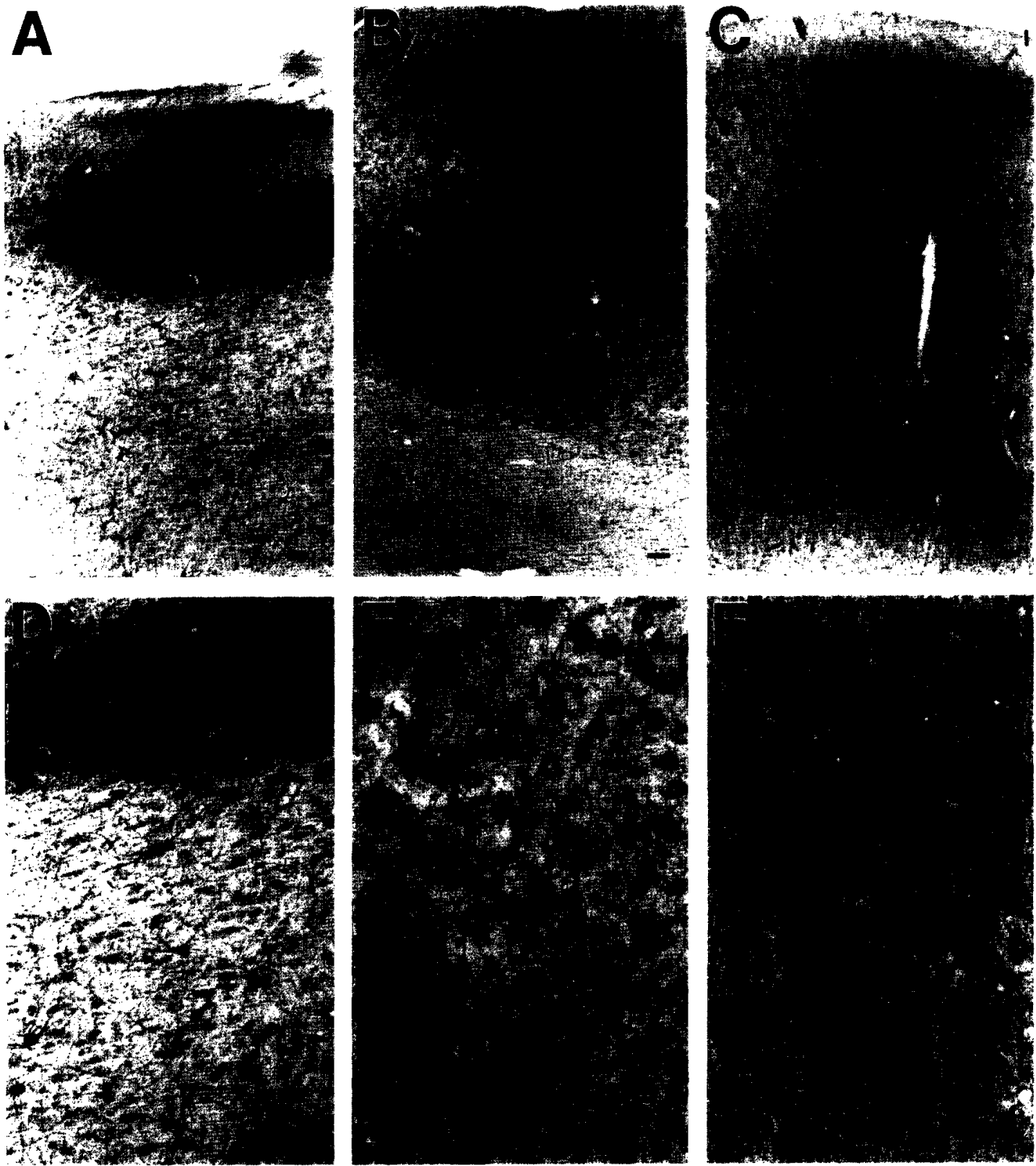

Fig. 3. Bright-field photomicrographs showing diaphorase-positive neurons in the olfactory cortex (A), dysgranular area $24(B)$, and eulaminate area $46(C)$. Frames D, E, and F show the cortices depicted respectively in A, B, C at higher magnification. Scale bars $=100 \mu \mathrm{m}$. 
by the subplate during development, suggests that they may be vestigial, having survived subplate elimination in postnatal life. ${ }^{26,64,116}$ Diaphorase co-localizes in neurons with somatostatin and neuropeptide $\mathrm{Y}^{29,46,118}$ which are major components of the transient subplate and are generated early in cortical development. ${ }^{46,57,64,103}$ The prevalence of diaphorase-positive neurons in the deep cortical layers which develop first $\mathrm{t}^{65,66,68,83-87}$ suggests that diaphorase may be expressed early in ontogeny as well.

Recent studies have provided evidence that diaphorase or NOS-positive neurons have a role in development. Prominent expression of NOS or diaphorase activity appears in the cortical plate of the developing rat and decreases substantially by birth. ${ }^{23,124}$ In addition, the expression of diaphorase
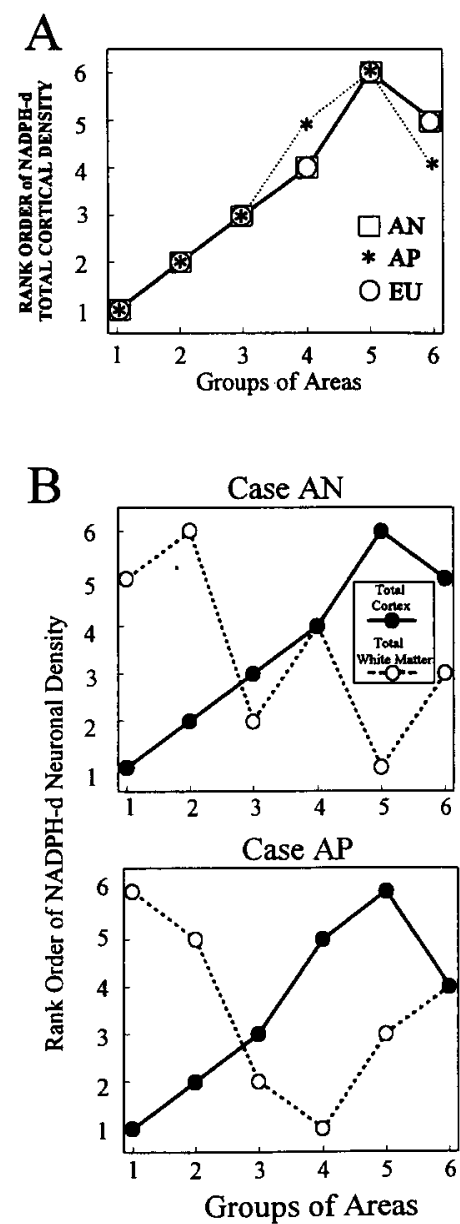

Fig. 4. (A) Line graphs showing the rank order of the regional distribution of diaphorase-positive neurons in three cases. The areas in each cortical category are listed in Table 1 and are arranged according to their laminar definition ( 1 olfactory, 6 best delineated eulaminate). Rank order depicts the density of NADPH diaphorase-positive neurons ( 1 highest density, 6 lowest density). The rank order of cortical categories in the three cases is highly correlated $(P<0.02)$. (B) The density of positive neurons (by rank) in the cortex (solid line) was inversely related to the density of labelled neurons in the underlying white matter (dashed line) as shown for cases AN (top) and AP (bottom). coincides with the time of peak refinement of axonal projections during development. Moreover, there is a concomitant decline in the expression of diaphorase (or NOS) as axons are eliminated during maturation. ${ }^{93,122}$ Finally, inhibition of NOS during development reduces the elimination of ipsilateral retinotectal projections within the visual system of the chick. ${ }^{123}$ The above evidence suggests that diaphorase neurons may have an active role in shaping the cortex.

In our own material we saw a clear relationship in the density of diaphorase-positive neurons in the cortex and white matter. Thus, positive neurons were abundant in the white matter below eulaminate areas where the cortical distribution is low, and they were comparatively sparsely distributed beneath olfactory and limbic cortices where the cortical distribution is high (Fig. 4B). This relationship is consistent with the idea that neuronal migration in limbic prefrontal cortices may precede that of eulaminate areas and may coincide with a time when diaphorase expression is high. Further developmental studies are necessary to address this issue.

The possible significance of diaphorase-positive neurons during development and in the adult cortex has recently been addressed in a post-mortem investigation of the brains of patients diagnosed with schizophrenia, which is thought to have a developmental origin. ${ }^{51,58}$ Compared to controls, brains of schizophrenic patients showed an overall decrease of diaphorase-positive neurons in areas 9 and 21 and in the subjacent white matter and an increase in the deep white matter. ${ }^{2,3}$ In view of our findings which indicate that diaphorase is enriched in limbic cortices, it may be interesting to examine these areas in schizophrenic brains particularly since the disorder affects disproportionally limbic cortices. ${ }^{89,121}$

\section{Functional implications}

Recent studies have implicated NO in synaptic plasticity in the hippocampus, cerebellum, and cortex ${ }^{18,19,33,44,79,80,98,99,104,114,125}$ (for review, see Refs 22, $100,106,107,127)$. We have shown that diaphorasepositive neurons are preponderant in agranular and dysgranular areas, which are the limbic component of the cortical mantle. Limbic cortices have an important role in mnemonic process. ${ }^{5,37,119.126}$ Moreover, the areas with a high number of diaphorase-positive neurons in the orbital and medial prefrontal cortices are the major recipients of input from other subcortical limbic structures including the amygdala and the hippocampus. ${ }^{14,11}$ Diaphorase is also enriched in neurons of the amygdala and subicular fields of the hippocampal formation ${ }^{20,70,81,105,114,115}$ which issue robust projections to the prefrontal cortex ${ }^{10,11}$ (for review, see Ref. 91). Thus, prefrontal limbic areas and subcortical limbic structures which are interconnected constitute a mnemonic network which may be influenced by NO. 

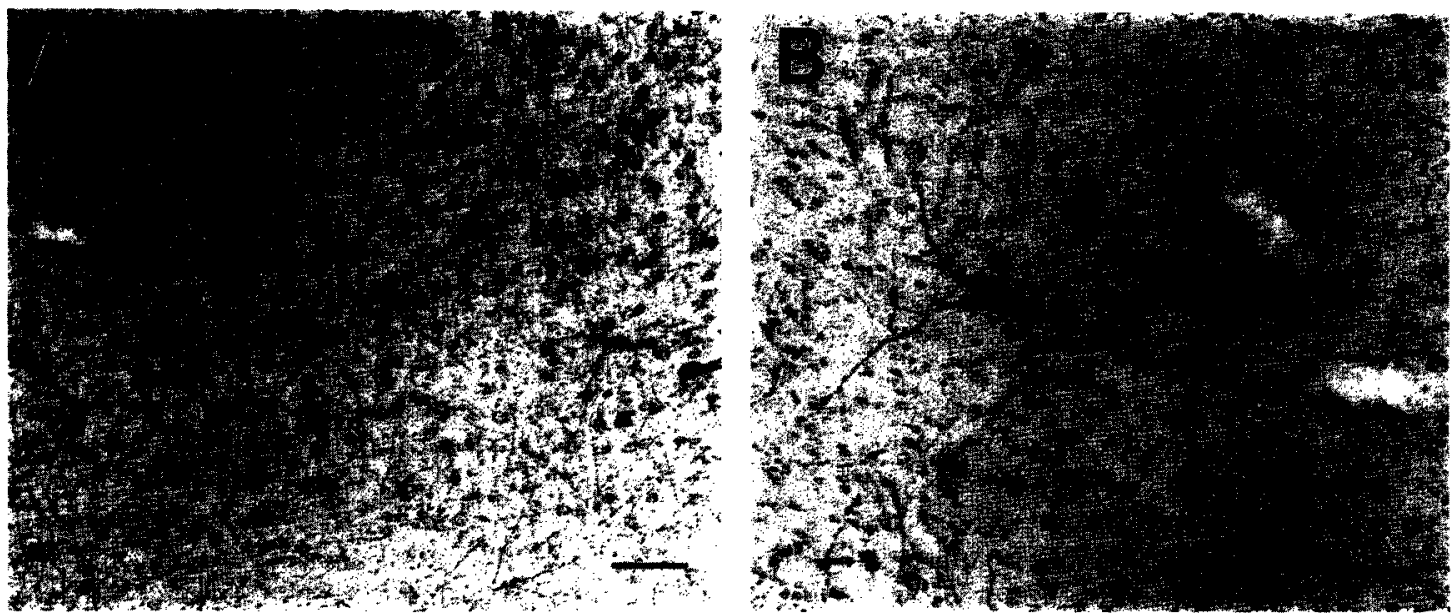

Fig. 5. Diaphorase-positive neurons in layers V-VI of dorsal area 9 (A) and in the proximal white matter underlying dorsal area $9(B)$. Scale bars $=100 \mu \mathrm{m}$.
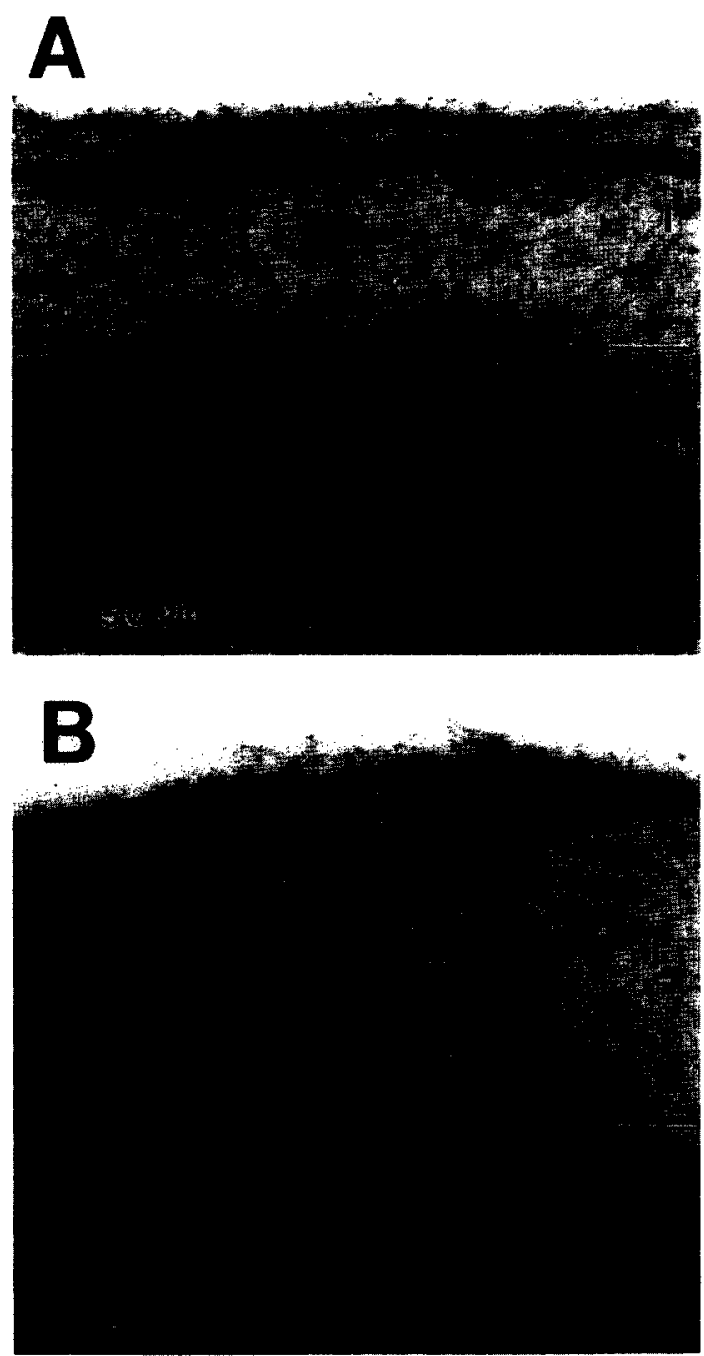

Fig. 6. Comparison of diaphorase-positive fibres in layer I of eulaminate area 8 (A) and limbic area 24 (B). Dense fibre labelling is shown in the central part of the top third of layer I (A); in contrast, only sparse labelling is seen in layer I of area 24 (B). Scale bars $=50 \mu \mathrm{m}$. 
Our results also showed that the density of diaphorase-positive neurons was generally higher in the orbital than in the medial component of the prefrontal segment of the limbic system. The above evidence suggests that the differential expression of diaphorase in the prefrontal cortex may follow functional lines. Basal prefrontal areas are connected with inferior temporal visual cortices ${ }^{6,8}$ which have been implicated in the analysis of visual features and their memory. ${ }^{39,40,48-50.108}$ Medial cortices are preferentially connected with dorsolateral visual cortices ${ }^{6}$ which have been implicated in visuospatial functions (for review, see Ref. 113). Additional studies are necessary to address whether the trend of diaphorase-positive neurons that we observed in the two prefrontal sectors distinguishes functional districts of temporal and dorsolateral visual areas as well.

\section{CONCLUSION}

Our findings suggest that the distribution of the class of neurons with diaphorase in prefrontal cortices and in the underlying white matter is not random. Diaphorase-positive neurons are most densely distributed in limbic prefrontal cortices. NO, produced in diaphorase-positive neurons, may have a role in the demonstrated function of prefrontal limbic cortices in memory. Moreover, the prevalence of diaphorase-positive neurons in the white matter appears to be inversely related to their density in the overlying cortex. This observation may reflect temporal differences in the development of distinct prefrontal cortices. Further studies are necessary to determine the function of diaphorase in prefrontal areas, its possible role in development and in the functional architecture of limbic areas in normal and pathological states.

\section{REFERENCES}

1. Aggleton J. P., Burton M. J. and Passingham R. E. (1980) Cortical and subcortical afferents to the amygdala of the rhesus monkey (Macaca mulatta). Brain Res. 190, 347-368.

2. Akbarian S., Bunney W. E., Potkin S. G., Wigal S. B., Hagman J. O., Sandman C. A. and Jones E. G. (1993) Altered distribution of nicotinamide-adenine-dinucleotide phosphate-diaphorase cells in frontal lobes of schizophrenics implies disturbances of cortical development. Archs Gen. Psychiat. 50, 169-177.

3. Akbarian S., Vinuela A., Kim J. J., Potkin S. G., Bunney W. E. and Jones E. G. (1993) Distorted distribution of nicotinamide-adenine-dinucleotide phosphate-diaphorase neurons in temporal lobe of schizophrenics implies anomalous cortical development. Archs Gen. Psychiat. 50, 178-187.

4. Amaral D. G. and Price J. L. (1984) Amygdalo-cortical projections in the monkey (Macaca fascicularis). J. comp. Neurol. 230, 465-496.

5. Bachevalier J. and Mishkin M. (1986) Visual recognition impairment follows ventromedial but not dorsolateral prefrontal lesions in monkeys. Behav. Brain Res. 20, 249-261.

6. Barbas H. (1988) Anatomic organization of basoventral and mediodorsal visual recipient prefrontal regions in the rhesus monkey. J. comp. Neurol. 276, 313-342.

7. Barbas H. (1992) Architecture and cortical connections of the prefrontal cortex in the rhesus monkey. In Advances in Neurology, Vol. 57 (eds Chauvel P., Delgado-Escueta A. V., Halgren E. and Bancaud J.), pp. 91-115. Raven Press Ltd, New York.

8. Barbas H. (1993) Organization of cortical afferent input to orbitofrontal areas in the rhesus monkey. Neuroscience 56, 841-864.

9. Barbas H. (1995) Anatomic basis of cognitive-emotional interactions in the primate prefrontal cortex. Neurosci. Biobehav. Rev. 19, 499-510.

10. Barbas H. and Blatt G. J. (1995) Topographically specific hippocampal projections target functionally distinct prefrontal areas in the rhesus monkey. Hippocampus, In press.

11. Barbas H. and De Olmos J. (1990) Projections from the amygdala to basoventral and mediodorsal prefrontal regions in the rhesus monkey. J. comp. Neurol. 301, 1-23.

12. Barbas H., Henion T. H. and Dermon C. R. (1991) Diverse thalamic projections to the prefrontal cortex in the rhesus monkey. J. comp. Neurol. 313, 65 94.

13. Barbas H. and Pandya D. N. (1987) Architecture and frontal cortical connections of the premotor cortex (area 6) in the rhesus monkey. J. comp. Neurol. 256, 211-218.

14. Barbas H. and Pandya D. N. (1989) Architecture and intrinsic connections of the prefrontal cortex in the rhesus monkey. J. comp. Neurol. 286, 353-375.

15. Barbas H. and Pandya D. N. (1991) Patterns of connections of the prefrontal cortex in the rhesus monkey associated with cortical architecture. In Frontal Lobe Function and Dysfunction (eds Levin H. S., Eisenberg H. M. and Benton A. L.), pp. 35-58. Oxford University Press, Oxford.

16. Beal M. F., Kowall N. W., Ellison D. W., Mazurek M. F., Swartz K. J. and Martin J. B. (1986) Replication of the neurochemical characteristics of Huntington's disease by quinolinic acid. Nature 321, 168-171.

17. Beal M. F., Kowall N. W., Swartz K. J. and Ferrante R. J. (1990) Homocysteic acid striatal lesions spare somatostain-neuropeptide Y-NADPH-diaphorase neurons. Neurosci. Lett. 108, 36-42.

18. Bohme G. A., Bon C., Stutzman J.-M. and Blanchard J.-C. (1991) Possible involvement of nitric oxide in long-term potentiation. Eur. J. Pharmac. 199, 379-381.

19. Bon C., Bohme G. A., Doble A., Stutzman J.-M. and Blanchard J.-C. (1992) A role for nitric oxide in long-term potentiation. Eur. J. Pharmac. 4, 420-424.

NSC $72 / 1-C$ 
20. Brady D. R., Carey R. G. and Mufson E. J. (1992) Reduced nicotinamide adenine dinucleotide phosphate-diaphorase (NADPH-d) profiles in the amygdala of human and New World monkey (Saimiri sciureus). Brain Res. 577, 236-248.

21. Bredt D. S., Glatt C., Hwang P. M., Fotuhi M., Dawson T. M. and Snyder S. H. (1991) Nitric oxide synthase protein and mRNA are discretely localized in neuronal population of mammalian central nervous system together with NADPH diaporase. Neuron 7, 615-624.

22. Bredt D. S. and Snyder S. H. (1994) Nitric oxide: A physiologic messenger molecule. A. Rev. Biochem. 63, $175-195$.

23. Bredt D. S. and Snyder S. H. (1994) Transient nitric oxide synthase neurons in embryonic cerebral cortical plate, sensory ganglia, and olfactory epithelium. Neuron 13, 301313.

24. Bruce C., Desimone R. and Gross C. G. (1981) Visual properties of neurons in a polysensory area in superior temporal sulcus of the macaque. J. Neurophysiol. 46, 369-384.

25. Chesselet M. F., Gonzales C. and Lin C. S. (1990) Ischemic damage in the striatum of adult gerbils: relative sparing of somatostatinergic and cholinergic neurons contrasts with efferent neurons. Expl Neurol. 110, 209-218.

26. Chun J. M. and Shatz C. J. (1989) Interstitial cells of the adult neocortical white matter are the remnant of the early-generated subplate neuron population. J. comp. Neurol. 282, 555-569.

27. Cipolloni P. B. and Pandya D. N. (1991) Golgi, histochemical, and immunocytochemical analyses of the neurons of auditory-related cortices of the rhesus monkey. Expl Neurol. 114, 104-122.

28. Dalkara T. and Moskowitz M. A. (1994) The complex role of nitric oxide in the pathophysiology of focal cerebral ischemia. Brain Pathol. 4, 49-57.

29. Dawson T. M., Bredt D. S., Fotuhi M., Hwang P. M. and Snyder S. H. (1991) Nitric oxide synthase and neuronal NADPH diaphorase are identical in brain and peripheral tissues. Proc. natn. Acad. Sci. U.S.A. 88, 7797-7801

30. Dawson T. M., Dawson V. L. and Snyder S. H. (1992) A novel neuronal messenger molecule in brain: the free radical, nitric oxide. Ann. Neurol. 32, 297-311

31. Dawson T. M. and Snyder S. H. (1994) Gases as biological messengers: nitric oxide and carbon monoxide in the brain. J. Neurosci. 14, 5I47-5159.

32. Dermon C. R. and Barbas H. (1994) Contralateral thalamic projections predominantly reach transitional cortices in the rhesus monkey. J. comp. Neurol. 344, 508-531.

33. Dinerman J. L., Dawson T. M., Schell M. J., Snowman A. and Snyder S. H. (1994) Endothelial nitric oxide synthase localized to hippocampal pyramidal cells: implications for synaptic plasticity. Proc natn. Acad. Sci. U.S.A. 91, 42144218.

34. Ferrante R. J. and Kowall N. W. (1984) Nicotinamide adenine dinucleotide phosphate-diaphorase (NADPH-d) histochemistry of the human caudate nucleus. Soc. Neurosci. Abstr. 10, 706.

35. Ferrante R. J., Kowall N. W., Beal M. F., Richardson E. P., Jr and Martin J. B. (1985) Selective sparing of a class of striatal neurons in Huntington's disease. Science 230, 561-563.

36. Ferriero D. M., Arcavi L. J., Sagar S. M., McIntosh T. K. and Simon R. P. (1988) Selective sparing of NADPH-diaphorase neurons in neonatal hypoxia-ischemia. Ann. Neurol. 24, 670-676.

37. Fuster J. M. (1989) The Prefrontal Cortex. 2 edn, Raven Press, New York.

38. Fuster J. M. (1993) Frontal lobes. Curr. Opin. Neurobiol. 3, 160-165.

39. Fuster J. M., Bauer R. H. and Jervey J. P. (198l) Effects of cooling inferotemporal cortex on performance of visual memory tasks. Expl Neurol. 71, 398-409.

40. Fuster J. M., Bauer R. H. and Jervey J. P. (1985) Functional interactions between inferotemporal and prefrontal cortex in a cognitive task. Brain Res. 330, 299-307.

41. Gallyas F. (1979) Silver staining of myelin by means of physical development. Neurol. Res. 1, 203-209

42. Geneser-Jensen F. A. and Blackstad T. W. (1971) Distribution of acetyl cholinesterase in the hippocampal region of the guinea pig. Z. Zellforsch. mikrosk. Anat. 114, 460-481.

43. Goldman-Rakic P. S. (1988) Topography of cognition: Parallel distributed networks in primate association cortex. A. Rev. Neurosci. 11, 137-156.

44. Haley J. E., Wilcox G. L. and Chapman P. F. (1992) The role of nitric oxide in hippocampal long-term potentiation. Neuron 8, 1-6.

45. Hashikawa T., Leggio M. G., Hattori R. and Yuri Y. (1994) Nitric oxide synthase immunoreactivity colocalized with NADPH-diaphorase histochemistry in the monkey cerebral cortex. Brain Res. 641, 341-349.

46. Hendry S. H. C., Jones E. G. and Emson P. C. (1984) Morphology, distribution, and synaptic relations of somatostatin- and neuropeptide $\mathrm{Y}$-immunoreactive neurons in rat and monkey neocortex. J. Neurosci. 4, $2497-2517$.

47. Hope B. T., Michael G. L., Knigge K. M. and Vincent S. R. (1991) Neuronal NADPH diaphorase is a nitric oxide synthase. Proc. natn. Acad. Sci. U.S.A. 88, 2811-2814.

48. Horel J. A. (1984) Cold lesions in inferotemporal cortex produce reversible deficits in learning and retention of visual discriminations. Physiol. Psychol. 12, 259-270.

49. Horel J. A. and Pytko D. E. (1982) Behavioral effect of local cooling in temporal lobe of monkeys. J. Neurophysiol $47,11-22$.

50. Horel J. A., Pytko-Joiner D. E., Voytko M. L. and Salsbury K. (1987) The performance of visual tasks while segments of the inferotemporal cortex are suppressed by cold. Behat. Brain Res. 23, $29-42$.

5I. Jakob H. and Beckman H. (1986) Prenatal development disturbances in the limbic allocortex in schizophrenia J. Neural. Transm. 65, 303-326.

52. Jones E. G. (1985) The Thalamus. Plenum Press, New York.

53. Kawamata T., Nakamura S., Akiguchi I., Kimura J., Kameyama M., Kimura H. and Takeda T. (1990) Effect of aging on NADPH-diaphorase neurons in lateral dorsal tegmental nucleus and striatum of mice. Neurobiol. Aging 11, 185192.

54. Koh J. and Choi D. W. (1988) Vulnerability of cultured cortical neurons to damage by excitotoxins: Differential susceptibility of neurons containing NADPH-diaphorase. $J$. Neurosci. 8, 2153-2163.

55. Koh J.-Y. and Choi D. W. (1988) Cultured striatal neurons containing NADPH-diaphorase or acetylcholinesterase are selectively resistant to injury by NMDA receptor agonists. Brain Res. 446, 374-378.

56. Koh J.-Y., Peters S. D. and Choi D. W. (1986) Neurons containing NADPH-diaphorase are selectively resistant to quinolinate toxicity. Science $\mathbf{2 3 4}, \mathbf{7 3 - 7 7}$ 
57. Kostovic I. and Rakic P. (1980) Cytology and time of origin of interstitial neurons in the white matter in infant and adult human and monkey telencephalon. J. Neurocytol. 9, 219-242.

58. Kovelman J. A. and Scheibel A. B. (1986) A neurohistologic correlate of schizophrenia. Biol. Psychiat. 19, $1601-1621$.

59. Kowall N. W. and Beal M. F. (1988) Cortical somatostatin, neuropeptide Y, and NADPH diaphorase neurons: normal anatomy and alterations in Alzheimer's disease. Ann. Neurol. 23, $105-114$.

60. Kowall N. W., Beal M. F., Ferrante R. J. and Martin J. B. (1985) Topography of nicotinamide adenine dinucleotide phosphate-diaphorase staining in rat striatum. Neurosci. Lett. 59, 61-66.

61. Kowall N. W., Ferrante R. J. and Beal M. F. (1987) Neuropeptide Y, somatostatin, and NADPH diaphorase in the human striatum: a combined immunocytochemical and enzyme histochemical study. Neuroscience 20, 817-828.

62. Kowall N. W., Ferrante R. J. and Martin J. B. (1987) Patterns of cell loss in Huntington's disease. Trends Neurosci. 10, 24-29.

63. Lamas S., Marsden P. A., Li G. K., Tempst P. and Michel T. (1992) Endothelial nitric oxide synthase: molecular cloning and characterization of a distinct constitutive enzyme isoform. Proc. natn. Acad. Sci. U.S.A. 89, 6348-6352.

64. Luskin M. B. and Shatz C. J. (1985) Studies of the earliest generated cells of the cat's visual cortex: Cogeneration of subplate and marginal zones. J. Neurosci. 5, 1062-1075.

65. Marin-Padilla M. (1970) Prenatal and early postnatal ontogenesis of the human motor cortex: A golgi study. I. The sequential development of the cortical layers. Brain Res. 23, 167-183.

66. Marin-Padilla M. (1972) Prenatal ontogenetic history of the principal neurons of the neocortex of the cat (Felis domestica). A golgi study. II. Developmental differences and their significances. Z. Anat. Entw. Gesch. 136, 125-142.

67. Matsumoto T., Nakane M., Pollock J. S., Kuk J. E. and Förstermann U. (1993) A correlation between soluble brain nitric oxide synthase and NADPH-diaphorase activity is only seen after exposure of the tissue to fixative. Neurosci. Lett. 155, 61-64.

68. McConnell S. K. (1991) The generation of neuronal diversity in the central nervous system. A. Rev. Neurosci. 14, 269-300.

69. McCulloch W. S. Some connections of the frontal lobe established by physiological neuronography. In The Frontal Granular Cortex and Behavior, pp. 95-105. McGraw-Hill, New York.

70. McDonald A. J., Payne D. R. and Mascagni F. (1993) Identification of putative nitric oxide producing neurons in the rat amygdala using NADPH-diaphorase histochemistry. Neuroscience 52, 97-106.

71. Mitrofanis J. (1989) Development of NADPH-diaphorase neurones in the rat's retina. Neurosci. Lett. 102, 165-172.

72. Mizukawa K., McGeer P. L., Vincent S. R. and McGeer E. G. (1988) Ultrastructure of reduced nicotinamide adenine dinucleotide phosphate (NADPH) diaphorase-positive neurons in the cat cerebral cortex, amygdala and caudate nucleus. Brain Res. 452, 286-292.

73. Mizukawa K., Vincent S. R., McGeer P. L. and McGeer E. G. (1988) Reduced nicotinamide adenine dinucleotide phosphate (NADPH)-diaphorase-positive neurons in the cat cerebral white matter. Brain Res. 461, 274-281.

74. Mizukawa K., Vincent S. R., McGeer P. L. and McGeer E. G. (1989) Distribution of reduced-nicotinamid-adenosinedinucleotide-phosphate diaphorase-positive cells and fibers in the cat central nervous system. $J$. comp. Neurol. 279, $281-311$.

75. Morecraft R. J., Geula C. and Mesulam M.-M. (1992) Cytoarchitecture and neural afferents of orbitofrontal cortex in the brain of the monkey. J. comp. Neurol. 323, 341-358.

76. Mufson E. J., Brady D. R. and Carey R. G. (1990) Reduced nicotinamide adenine dinucleotide phosphate-diaphorase (NADPH-d) histochemistry in the hippocampal formation of the new world monkey (Saimiri sciureus). Brain Res. 516, 237-247.

77. Mufson E. J. and Brandabur M. M. (1994) Sparing of NADPH diaphorase striatal neurons in Parkinson's and Alzheimer's diseases. NeuroReport 5, 705-708.

78. Nauta W. J. H. and Feirtag M. (1986) Fundamental Neuroanatomy. W. H. Freeman and Company, New York.

79. Nowicky A. V. and Bindman L. J. (1993) The nitric oxide synthase inhibitor, $N$-monomethyl-L-arginine blocks induction of a long-term potentiation-like phenomenon in rat medial frontal cortical neurons in vitro. J. Neurophysiol. 70, $1255-1259$.

80. O'Dell T. J., Hawkins R. D., Kandel E. R. and Arancio O. (1991) Tests of the roles of two diffusible substances in long-term potentiation: Evidence for nitric oxide as a possible early retrograde messenger. Proc. natn. Acad.Sci. U.S.A. 88, $11285-11289$.

81. Pitkanen A. and Amaral D. G. (1991) Distribution of reduced nicotinamide adenine dinucleotide phosphate diaphorase (NADPH-d) cells and fibers in the monkey amygdaloid complex. J. comp. Neurol. 313, 326-348.

82. Potter H. and Nauta W. J. H. (1979) A note on the problem of olfactory associations of the orbitofrontal cortex in the monkey. Neuroscience, 4, 361-367.

83. Rakic P. (1972) Mode of cell migration to the superficial layers of fetal monkey neocortex. J. comp. Neurol. 145, 61-84.

84. Rakic P. (1974) Neurons in rhesus monkey visual cortex: systematic relation between time of origin and eventual disposition. Science 183, 425-426.

85. Rakic P. (1982) Early developmental events: cell lineages, acquisition of neuronal positions, and areal and laminar development. Neurosci. Res. Prog. Bull. 20, 439-451.

86. Rakic P. (1988) Defects of neuronal migration and the pathogenesis of cortical malformations. In Progress in Brain Research (eds Boer G. J., Feenstra M. G. P., Mirmiran M., Swaab D. F., Van Haaren F.), pp. 15-37. Elsevier Science Publishers B.V.

87. Rakic P. (1988) Specification of cerebral cortical areas. Science 241, 170-176.

88. Ray J. P. and Price J. L. (1993) The organization of projections from the mediodorsal nucleus of the thalamus to orbital and medial prefrontal cortex in macaque monkeys. J. comp. Neurol. 337, 1-31.

89. Reynolds J. P. (1989) Beyond the dopamine hypothesis. The neurochemical pathology of schizophrenia. Br. J. Psychiat. 155, 305-316.

90. Rosene D. L., Roy N. J. and Davis B. J. (1986) A cryoprotection method that facilitates cutting frozen sections of whole monkey brains from histological and histochemical processing without freezing artifact. J. Histochem. Cytochem. 34, 1301-1315. 
91. Rosene D. L. and Van Hoesen G. W. (1987) The hippocampal formation of the primate brain. A review of some comparative aspects of cytoarchitecture and connections. In Cerebral Cortex, Vol. 6 (eds Jones E. G. and Peters A.), pp. 345 455. Plenum Publishing Corporation, New York.

92. Rosenkilde C. E. (1983) Functions of the prefrontal cortex. Acta physiol. scand. Suppl. 514, $1-43$.

93. Roskams A. J., Bredt D. S., Dawson T. M. and Ronnett G. V. (1994) Nitric oxide mediates the formation of synaptic connections in developing and regenerating olfactory receptor neurons. Neuron 13, 289-299.

94. Sandell J. H. (1985) NADPH diaphorase cells in the mammalian inner retina. J. comp. Neurol. 238, 466-472.

95. Sandell J. H. (1986) NADPH diaphorase histochemistry in the macaque striate cortex. J. comp. Neurol. 251, 388-397.

96. Sandell J. H., Graybiel A. M. and Chesselet M. F. (1986) A new enzyme marker for striatal compartmentalization: NADPH diaphorase activity in the caudate nucleus and putamen of the cat. J. comp. Neurol. 243, 326-334.

97. Scherer-Singler U., Vincent S. R., Kimura H. and McGeer E. G. (1983) Demonstration of a unique population of neurons with NADPH-diaphorase histochemistry. J. Neurosci. Meth. 9, 229-234.

98. Schuman E. M. and Madison D. V. (1991) A requirement for the intercellular messenger NO in LTP. Science 263, 1503-1506

99. Schuman E. M. and Madison D. V. (1994) Locally distributed synaptic potentiation in the hippocampus. Science 263, $532-536$.

100. Schuman E. M. and Madison D. V. (1994) Nitric oxide and synaptic function. A. Rev. Neurosci. 17, 153-183.

101. Scott J. W., McDonald J. K. and Pemberton J. L. (1987) Short axon cells of the rat olfactory bulb display NADPH-diaphorase activity, neuropeptide Y-like immunoreactivity, and somatostatin-like immunoreactivity. $J$. comp. Neurol. 260, 378-391.

102. Sestan N. and Kostovic I. (1994) Histochemical localization of nitric oxide synthase in the CNS. Trends Neurosci. 17, 105-106.

103. Shatz C. J., Chun J. M. and Luskin M. B. (1988) The role of the subplate in the development of the mammalian telencephalon. In Cerebral Cortex (eds Peters A. and Jones E. G.), pp. 35-58. Plenum, New York.

104. Shibuki K. and Okada D. (1991) Endogenous nitric oxide release required for long-term synaptic depression in the cerebellum. Nature 349, 326-328.

105. Sims K. S. and Williams R. S. (1990) The human amygdaloid complex: a cytologic and histochemical atlas using Nissl, myelin, acetylcholinesterase and nicotinamide adenine dinucleotide phosphate diaphorase staining. Neuroscience 36, 449-472.

106. Snyder S. H. (1992) Nitric oxide: First in a new class of neurotransmitters? Science 257, 494496.

107. Snyder S. H. (1992) Nitric oxide and neurons. Curr. Opin. Neurobiol. 2, 323-327.

108. Tanaka K., Saito H.-A., Fukada Y. and Moriya M. (1991) Coding visual images of objects in the inferotemporal cortex of the macaque monkey. $J$. Neurophysiol. 66, 170-189.

109. Thomas E. and Pearse A. G. E. (1961) The fine localization of dehydrogenases in the nervous system. Histochemie 2, 266-282.

110. Thomas E. and Pearse A. G. E. (1964) The solitary active cells: Histochemical demonstration of damage-resistant nerve cells with a TPN-diaphorase reaction. Acta neuropath., Berlin 3, 238-249.

111. Tracey W. R., Nakane M., Pollock J. S. and Förstermann U. (1993) Nitric oxide synthases in neuronal cells, macrophages, and endothelium are NADPH diaphorases, but represent only a fraction of total cellular NADPH diaphorase activity. Biochem. biophys. Res. Commun. 195, 1035-1040.

112. Uemura Y., Kowall N. W. and Beal M. F. (1990) Selective sparing of NADPH-diaphorase somatostatin-neuropeptide $\mathrm{Y}$ neurons in ischemic gerbil striatum. Ann. Neurol. 27, 620-625.

113. Ungerleider L. and Mishkin M. (1982) Two cortical visual systems. In Analysis of Visual Behavior (eds Ingle D. J., Goodale M. A. and Mansfield R. J. W.), pp. 549-586. MIT Press, Cambridge.

114. Valtschanoff J. G., Weinberg R. J., Kharazia V. N., Nakane M. and Schmidt H. H. H. W. (1993) Neurons in the rat hippocampus that synthesize nitric oxide. J. comp. Neurol. 331, 111-121.

115. Valtschanoff J. G., Weinberg R. J., Kharazia V. N., Schmidt H. H. H. W., Nakane M. and Rustioni A. (1993) Neurons in the rat cerebral cortex that synthesize nitric oxide; NADPH diaphorase histochemistry, NOS immunocytochemistry, and colocalization with GABA. Neurosci. Lett. 157, 157-161.

116. Valverde F, and Facal-Valverde M. V. (1987) Transitory population of cells in the temporal cortex of kittens. Devl Brain Res. 32, 283-288.

117. Villalba R. M., Martinez-Murillo R., Blasco I., Alvarez F. J. and Rodrigo J. (1988) C-PON containing neurons in the rat striatum are also positive for NADPH-diaphorase activity. A light microscope study. Brain Res. 462, 359-362.

118. Vincent S. R., Johansson O., Hökfelt T., Skirboll L., Elde R. P., Terenius L., Kimmel J. and Goldstein M. (1983) NADPH-diaphorase: A selective histochemical marker for striatal neurons containing both somatostatin- and avian pancreatic polypeptide (APP)-like immunoreactivities. J. comp. Neurol. 217, 252-263.

119. Voytko M. L. (1985) Cooling orbital frontal cortex disrupts matching-to-sample and visual discrimination learning in monkeys. Physiol. Pschol. 13, 219-229.

120. Walker A. E. (1935) The retrograde cell degeneration in the thalamus of macacus rhesus following hemidecortication. J. comp. Neurol. 62, 407-419.

121. Weinberger D. R. (1988) Schizophrenia and the frontal lobe. Trends Neurosci. 11, 367-370.

122. Williams C. V., Nordquist D. and McLoon S. C. (1994) Correlation of nitric oxide synthase expression with changing patterns of axonal projections in the developing visual system. J. Neurosci. 14, 1746-1755.

123. Wu H. H., Williams C. V. and McLoon S. C. (1994) Involvement of nitric oxide in the elimination of a transient retinotectal projection in development. Science 265, 1593-1596.

124. Yan X. X., Garey L. J. and Jen L. S. (1994) Development of NADPH-diaphorase activity in the rat neocortex. Devl Brain Res. 79, 29-38.

125. Zhou M., Small S. A., Kandel E. R. and Hawkins R. D. (1993) Nitric oxide and carbon monoxide produce activity-dependent long term synaptic enhancement in hippocampus. Science 260, 1946-1950.

126. Zola-Morgan S. and Squire L. R. (1993) Neuroanatomy of memory. A. Rev. Neurosci. 16, 547-563.

127. Zorumski C. F. and Izumi Y. (1993) Nitric oxide and hippocampal synaptic plasticity. Biochem. Pharmac. 4, $777-785$. 